\title{
Confluent Education in a Counseling Psychology Program
}

\author{
Paul Jenkins*, Augusto Penafiel, B. Charles Tatum \\ Department of Psychology, National University, San Diego, CA, USA \\ Email: *pjenkins@nu.edu
}

How to cite this paper: Jenkins, P., Penafiel, A., \& Tatum, B. C. (2018). Confluent Education in a Counseling Psychology Program. Psychology, 9, 1957-1978. https://doi.org/10.4236/psych.2018.98113

Received: June 26, 2018

Accepted: August 4, 2018

Published: August 7, 2018

Copyright $\odot 2018$ by authors and Scientific Research Publishing Inc. This work is licensed under the Creative Commons Attribution International License (CC BY 4.0).

http://creativecommons.org/licenses/by/4.0/

\begin{abstract}
This study examined the effectiveness of using a humanistic teaching model in a graduate level counseling program. Specifically, the Confluent Education model was implemented in a Master's level, psychological assessment course. The results of a knowledge test suggested only marginally significant differences between the experimental and traditionally taught (control) groups. However, the results from student feedback clearly showed that the students in the experimental group preferred Confluent Education over the traditional model, which suggests that Confluent Education is more engaging and increases the student's confidence in their counseling and critical thinking skills.
\end{abstract}

\section{Keywords}

Confluent Education, Psychotherapy Education, Humanistic Education

\section{Introduction}

Confluent Education (CE) refers to a process of holistic learning, involving multiple aspects of the learner, including his or her emotions, spirit, and ideation (Shapiro, 1995, 1997). Rather than focusing on simply memorizing facts or learning particular skills, CE seeks to engage the "whole learner" in a process of personal, as well as academic or professional growth. To do this, the course or program must be open to providing education through a variety of methods and styles, engage each unique individual in the classroom, and focus as much on helping the students learn about themselves and others, as on the traditional subject matter or skills (Brown, 1975).

In America, the concept of learner-centered, or whole person education goes back a long way, but exists against the backdrop of an educational history 
marked by extremes of coercion and cultural disruption (Urban, 2014). For instance, the "education" of Native Americans was often implemented through forced conversion to Christianity, and implantation of Western values, beliefs, and behavioral patterns. The educational treatment of Caucasian colonist's children was not too dramatically different. Children were typically conceptualized as "empty receptacles" for academic and religious "knowledge".

The progressive movement in American society (late $19^{\text {th }}$ century, to early $20^{\text {th }}$ century) included a reexamination and reform of the educational system (Urban, 2014). Without going into too much detail that is outside the purview of this paper, a very brief list of these changes would include: 1) universal education, 2) expansion and reorganization of the curriculum, 3) improved facilities and training of teachers and administrators, and 4) innovations in pedagogy. It is this last change that we are focused on. The huge influx of immigrants from South and Eastern Europe in the early $20^{\text {th }}$ century created tremendous stress on and expansion of public education. While much of this education stressed acculturation and work skills, there was the beginning of a counter-movement. This movement, led by people like G. Stanley Hall and John Dewey, stressed the importance of an education that worked with, and supported the process of individual development (Urban, 2014). In other words, an effective educational system should begin with awareness of the student's capacities, existing beliefs, skills, and interests. It should be sensitive to the fact that these factors are strongly influenced by the student's cultural background. And finally, education goes beyond the immediate content of the course and should foster the spiritual, social, and moral development of the individual.

By the 1960s, the progressive movement had transformed into something different; a collection of different movements (civil rights, women's rights, the anti-war movement, free speech) that impacted various aspects of American culture, including the educational system (Urban, 2014). On many college campuses, students demanded more equality between faculty and students, more choice in curriculum, courses that were more directly relevant to their lives, and a teaching style that was more egalitarian and inclusive of student's input.

These issues shared a philosophical foundation in humanism and it followed that humanistic education became a movement in itself. A leader in this was Rogers (1969). By the 1960s, he was already a well-known figure in clinical psychology, having developed an approach to psychotherapy (client-centered therapy) that was transforming the field. As someone who was active as a teacher of graduate students in psychology, Rogers was concerned about the standard assumptions and practices he found there, and felt strongly that a number of changes would lead to better educational outcomes. After observing a number of psychology departments in America, he concluded that they exhibit a number of disturbing underlying assumptions: 1 ) students cannot be trusted to pursue their own learning, 2) the ability to pass tests is the best criterion for judging professional promise, 3) evaluation is education (exams and graded papers as the beginning and end of education), 4) lecture/teacher presentation equals learning, 
5) knowledge equals the progressive accumulation of information, 6) the "truths" of psychology are known, 7) creative practitioners develop from passive learners, 8) "weeding out" weak learners is a good way of producing good clinicians, and 9) students should be regarded as manipulatable objects, not as persons. Rogers proposed to replace these assumptions, and the educational practices they led to, with a system that 1) includes the students in the planning and implementation of the program, 2) has the highest level of freedom possible for students to pursue their own academic interests, choose their own educational tasks, and design their own evaluation of learning, and 3) has evaluations that focus on the student's exhibited knowledge, but also their creativity, critical thinking skills, and the effectiveness of practical applications of that knowledge. These changes are based on "replacement" assumptions that include, 1) students naturally have the desire and potential to learn, if a suitable environment is provided, 2) learning should be rooted in reality-making it more relevant and meaningful for students, 3) learning and evaluation of learning should be as self-directed as possible, in order to maximize individual responsibility and personal "buy in".

This humanistic approach to education was central to the development of Confluent Education (Brown, 1971). As an example or "model" of the humanistic approach, CE was designed to increase student's active engagement in the learning process, thus increasing their attainment and retention of information, as well as their mastery of specific skills. Confluent education refers to the integration of both affective and cognitive processes in the educational process. First developed in the early 1970s, it was a formal response to concerns that had been emerging in the 1960s regarding the limitations of educational models that focused primarily on cognitive aspects of learning, and disregarded more personal and emotional aspects of the learner (Rogers, 1969, 1983). It also grew out of the field of Gestalt psychotherapy, which sought to create conditions for individual expression, rather than encouraging the therapist to "dominate" psychotherapy with his or own preconceptions about the client and need to control the sessions.

It is postulated that when the "whole" student is not addressed in the learning process, less motivation, attention, and energy is brought to the learning process by the student (and often the instructor as well) and thus, less is actually learned (Brown, 1971). Not only that, but by engaging the "whole" student, the information and skills learned are more likely to be deeply integrated in their personality, leading to better retention, and smoother, more effective execution of skills.

CE was experimented with on a limited basis during the 70 's and 80 's, but has since largely disappeared from the literature. In fact, it could be argued that a more humanistic approach to education has been largely forgotten, or left behind, with our collective interest more focused on technical aspects of teaching, such as designing curriculum standards, or teaching to specific learning styles (Moore, 2005). However, the humanistic approach has continued, in a limited way, with what is commonly known as learner-centered teaching (LCT) (Doyle, 2011). The term limited way is used here because LCT tends to be offered as a 
general approach, or even a collection of teaching techniques, rather than a revolutionary restructuring of the educational system (Doyle, 2011). As a general approach, LCT asserts the importance of students being actively engaged in their learning and thus working harder than the teacher. As a collection of techniques, it promotes practices that create that engagement. But, while many of the techniques of LCT are applicable to CE, the core philosophy is less distinct and developed. Also, LCT is more practically oriented, and thus is likely to be utilized across a wide variety of educational settings.

On the other hand, there is a natural demand, given the nature of the subject matter, within the field of professional counseling, to address our students as "whole people", with unique individual strengths and challenges, through a person-centered paradigm. That is why this study has utilized Confluent Education as its model, while acknowledging the overlapping concepts of Humanistic Education and LCT. Many of the specific teaching techniques were originally conceptualized in the Humanistic and Confluent Education models, but more fully developed in LCT. For instance:

1) Classroom Configuration/Format-rather than seat students in rows, facing the front of the classroom, we configured the classroom in a "flying V", with the rows of students facing each other as much as the instructor. This facilitates more student interaction during class. In a traditional model, student interaction is typically seen as a "distraction", taking away from the focus on the instructor. In the CE model, student interaction is seen as vital to learning. There should also be an attempt to create a pleasant, supportive learning environment. The sights and smells of the classroom are seen as vital to the learning process. Casual dress is encouraged and a relaxation of traditional student/instructor roles (are we comfortable not being called doctor or professor?) encourages more personal engagement with the course experience.

2) Student Discussion - in the traditional model, classroom discussion is kept to a minimum and typically takes the form of the Socratic method of teaching, with the instructor asking specific questions to specific students, to foster reasoning. In the CE model, student discussion is more central to the learning process, and should start with a more open-ended question/topic that fosters student imagination and integration with pre-existing knowledge and experience. Students should be encouraged to share about themselves-who they are and how their experiences in life relate to the class content.

3) Flexible Assignments-in the traditional model, the instructor completely controls what assignments are utilized in a particular course. In the CE model, students are given much more control of their choice of assignments and even scoring method, to maximize their personal engagement and relevance of the course work. This specific teaching method relates to the general concept of power-sharing between students and instructors. To what extent is an instructor willing to negotiate course material, assignments, due dates, grading scales, classroom format, office hours, etc.? 
4) Experiential Learning - in the traditional model, much of the instruction is conducted through instructor lecture. While the use of PowerPoint technology and video has made this technique more stimulating, it has not changed the basic dynamic of students being the passive receivers of course content from the instructor. In $\mathrm{CE}$, the instructor is invited to develop experiential classroom assignments, giving the students a "living experience" of the course content. What this looks like is obviously different from course to course, but an example would be having students actively practice basic counseling skills a much greater amount of the time, over hearing an instructor's lecture about those skills, or even watching a video of someone else doing them.

5) Teaching to all the Senses-in the traditional model, instruction is primarily auditory. In CE, there is an attempt to present material in as many ways as possible. This can be done through multimedia, or the use of imaginative classroom activities that are kinesthetic, as well as auditory and visual.

6) Focusing on Patterns-rather than data points. In the traditional model, there is a focus on presenting specific information, then testing our students on how well they memorize it. In the CE model, teaching specific information is seen as secondary to helping our students identify and develop the organizing principles behind the data. As an instructor of mine used to say, "You can look up the facts at home; I want you to understand how the facts are organized".

7) Repetition and Elaboration-in the traditional model, information is provided once and then the class moves on. Again, the challenge is for the students to do $\mathrm{R} \& \mathrm{R}$ (remember and regurgitate). In $\mathrm{CE}$, the main course content is reinforced through repetition (optimally through various modes/senses), and elaboration through classroom discussion, "personalization" (integrating material with pre-existing knowledge and experience), and assignments that require the student to develop the content through lived experience.

Together, these techniques can provide a learning experience that is significantly more engaging and effective (Doyle, 2011; Wright, 2011). This author has personally found that incorporating these concepts and techniques into the classroom has made the teaching process more energized and even fun! Learning more about our students, how they feel about the course content, helping them integrate the material into their developing personal and professional sense of self, and finding ways of making the material personal, relevant, and experienced, rather than just memorized, can be a deeply rewarding experience for an instructor.

\section{Project Design}

The purpose of this project was to measure the effect of conducting a Master's level psychological assessment course using the CE model. It is one thing to claim that a particular system of learning is "engaging and effective" and another to provide evidence that it really is. In order to measure this, the authors had to first specify what outcomes they were hoping for. The agreement was that the data should be evaluated based on the Kirkpatrick four-level model of evaluation 
(Chyung, 2008; Kirkpatrick, 1996). He felt that a training program could be evaluated based on the participant's 1) reaction to the program, 2) actual learning, 3) extent of behavior change, and 4) any final results, i.e. change in work performance. For this study, the first level evaluation was done with a student feedback form, asking the students various questions about their feeling about and response to the course. The second level evaluation was done with a pre-post test system that measured how much the students learned, in a number of key academic areas, during the course. It was decided that a third level evaluation was not appropriate for this study as the assessment skills being taught did not exist prior to the course, so there could not be a pre-post test of behavior change. However, a fourth level evaluation could be done, because future application of skills learned in the course could be measured, at least indirectly through a questionnaire completed by the students, after they had taken four more counseling classes, asking about how prepared they felt by their assessment course for that part of their emerging counseling skills. There was consideration of waiting for evaluation forms from practicum supervisors, but this idea was dropped because there was no way to establish inter-rater reliability among the clinical supervisors.

\section{Method}

Permission was granted by the Dean of the College of Letters and Sciences at National University to approach a number of instructors and ask if they would be willing to participate in this study by using an upcoming course as a control group. Those who agreed to participate would need to 1) have their students complete the pre-test on the first day of class (see Appendix A), 2) have their students complete the post-test on the final day of class (see Appendix A), 3) have their students complete the student feedback form on the final day of class (see Appendix B), and 4) otherwise teaching their course in the "treatment as usual" way they have in the past. As a result of these restrictions, there were 14 students in the experimental group and 19 students in the control group (see Results below). Two instructors with upcoming PSY612A courses assigned to them agreed to participate in the research project. They were sent copies of the pre-test, post-test, and feedback form to distribute to their students. At the end of the month-long course, they sent back as many completed forms as they had, each identified only with the student's initials so the forms could be compiled without sacrificing anonymity. The same procedure was used for the experimental group, except that course was taught using techniques based on CE principles. The completed forms were collected by the principle researchers and stored in a locked file cabinet at the National University's Rancho Cordova Learning Center. The data was entered into an Excel spreadsheet, which was then utilized to analyze the results.

In the experimental group, the instructor utilized the teaching techniques of CE. This included: 
1) Tables and chairs placed perpendicular to the walls, which provides an open room experience allowing the students to face each other, and for the teacher to be physically closer to the students.

2) Encourage experiential activities related to class content (i.e., self-administration, scoring and interpretation of psychological instruments; role-play mental disorders being discussed, students role-play parents or spouses, counselor and client).

3) Request students provide samples of questions for the examinations. This experience was intended to encourage students to be actively involved in the assessment process.

4) Reduce the points for the midterm and final exam. Increase the percentage of the grade given for a personal project in which the student shared personal experiences related to what was learned in class (i.e., writing a letter to a love one, writing a poem, singing a song, compose a song, or other artistic expression).

5) Discuss the answers of the examinations right after it is taken. This approach can solidify or correct the learning on the topics discussed.

6) Share the results of examinations or grading activities no later than the following school day. This approach is intended to keep the students motivated and engaged in their grading process.

7) Use a modified "flipped classroom" technique, where the students do most of their 'basic learning' of the material at home, via reading assignments, then spend much more time in class leading concept engagement exercises.

In the control groups, the instructors were directed to teach their course as they normally would. This "treatment as usual" instruction was necessary because there was more than one instructor involved in the control groups and we did not want to "force" any particular style on these instructors. Moreover, we did not want to direct an instructor to provide education that, in their assessment, was less effective than what they would "normally" do.

The Pre and Post tests were divided into different sections of questions, related to different areas of learning (see Appendix A and Appendix C). Rote questions addressed the memorization of specific clinical information, pertinent to psychological assessment. Critical thinking questions addressed the ability to integrate information, process it, and reach logical clinical conclusions utilizing the information. Diagnostic questions addressed the need for students to be able to reach accurate DSM psychodiagnostic conclusions. The areas were differentiated because it was possible that CE might impact one type of learning (critical thinking, for instance) more or less than another.

The Feedback Form (see Appendix B and Appendix C) was divided into General Learning, Critical Thinking, Generalized Knowledge/Skills, and CE specific feedback for the same reason. Also, it made sense to align the areas in the feedback form with those in the pre/post tests, to evaluate how students felt they learned in those areas, whether or not they thought they learned as much or more than students in a traditional classroom, what the student's attitudes/beliefs about 
their learning and their experience were, and how these attitudes and beliefs compare to those who were in the control groups?

\section{Results}

Demographic information was not gathered for the subjects. They were simply all students enrolled in two clinical assessment courses (PSY612A) as part of the Master of Arts in Counseling program at National University. There were a total of 19 students in the control groups and 14 students in the experimental group. The difference in sample size did not affect the results for the feedback, but may have limited the effects of the treatment on the knowledge test due to low power (see the next paragraph).

The results for the knowledge tests are shown in Table 1. The difference between the pre-test and post-test for the experimental and control groups was not statistically significant for any of the types of questions (rote, critical thinking, or diagnostic). The statistical results for each type of question were:

Rote: $\mathrm{F}(1,31)=2.67, p<.11($ power $=.35)$

Critical Thinking: $\mathrm{F}(1,31)=.27, p>.60($ power $=.08)$

Diagnostic: $\mathrm{F}(1,31)=1.04, p<.31($ power $=.17)$

The interaction between the pre/post test and group for the rote questions was close to significant: $\mathrm{F}(1,31)=2.67, p<.12$. As shown in Table 1 , the control-group mean score for rote questions rose from $45.56 \%$ correct (pre-test) to $52.63 \%$ (post-test), while the experimental-group mean score rose from $44.20 \%$ (pre-test) to $64.73 \%$ (post-test). When examining the interaction between testing (pre/post) and groups (experimental/control) for the critical thinking questions, there was no statistical difference between the pre- and post-tests for the two groups: $\mathrm{F}(1,31)<1.00$. Likewise, there was no pre-post differences for the diagnostic questions: $\mathrm{F}(1,31)=1.04, p>.3$.

With respect to the student feedback, the results were quite different from the pre/post-tests. As noted in the method section, the feedback items were divided into four sets (general learning, critical thinking, generalized knowledge/skill, and feedback specific to confluence education). The results from the student feedback are shown in Table 2. For three of the four sets, students in the experimental group rated the class as significantly superior (on a 5-point agreement

Table 1. Average percent correct for the pre-and post-test knowledge questions (rote, critical thinking, and diagnostic) for the experimental (confluence) and control (treatment as usual) groups.

\begin{tabular}{ccccc}
\hline \multirow{2}{*}{ Question Type } & \multicolumn{2}{c}{ Pre-Test } & \multicolumn{2}{c}{ Post-Test } \\
\cline { 2 - 5 } & Control & Experimental & Control & Experimental \\
\hline Rote Questions & $45.56(14.85)$ & $44.20(13.53)$ & $52.63(21.28)$ & $64.73(18.28)$ \\
Critical Thinking & $42.11(16.19)$ & $51.43(27.98)$ & $71.58(22.43)$ & $85.71(19.89)$ \\
Diagnostic & $55.81(16.41)$ & $69.20(13.36)$ & $77.41(11.22)$ & $85.42(9.91)$ \\
\hline
\end{tabular}

Note: Standard deviations are in parentheses. 
Table 2. Average student feedback ratings (general, critical thinking, generalized, and confluence specific) for the experimental (confluence) and control (treatment as usual) groups.

\begin{tabular}{ccc}
\hline Feedback Type & Control & Experimental \\
\hline General (4 items) & $14.18(3.19)$ & $17.36(2.41)$ \\
Critical Thinking (2 items) & $7.64(2.25)$ & $9.29(1.54)$ \\
Generalized Knowledge/Skill (2 items) & $8.27(1.85)$ & $9.14(1.23)$ \\
Confluence Specific (4 items) & $15.27(4.10)$ & $18.21(2.86)$ \\
\hline
\end{tabular}

Note: Feedback ratings are expressed as the ratings level (5-point scale) multiplied by the number of items. Standard deviations are in parentheses.

scale) to the control group. The only exception was for the two items that asked about generalized knowledge/skill ("I feel I can apply what I learned...... helped me to become a better counselor"): $\mathrm{F}(1,23)=1.20, p>.2$.

The results for the other sets were:

General Learning: $\mathrm{F}(1,23)=8.08, p<.01$

Critical Thinking: $\mathrm{F}(1,23)=4.74, p<.05$

Confluence Specific: $\mathrm{F}(1,23)=4.47, p<.05$

\section{Discussion}

The purpose of this study was to examine the effectiveness of the CE model of education with students in a clinical assessment course taken as part of their Master's level counseling psychology program at National University. The results of pre- and post-tests, as well as feedback forms were compared between the experimental group and the two control groups. As noted in the Results section, there was a finding of no significant differences between the experimental and control groups with respect to the pre-test/post-test differences. This suggests, on the face of it, that there may not be a significant difference between the $\mathrm{CE}$ model of teaching and the "traditional" one. However, there were a number of limitations in the study that made that conclusion questionable. First of all, there were a very small number of subjects in both groups, thus limiting the power of the results. Second, there were different teachers implementing the control and experimental courses, suggesting that individual differences between the teachers may account for any differences in quality of learning, or in the case or our current results, the lack of significant differences in outcome. Finally, because of the nature of the methods used, it was difficult to assess what teaching modality was utilized in the control group. It is possible that the control group instructor, directed to teach the course in the "treatment as usual" style, naturally taught in a humanistic manner, not significantly different than the teaching method experimental group received. Addressing these limitations could include: 1) at least two more cycles of the experiment be conducted to increase the overall number of subjects in both conditions, 2) the same instructor be used for both conditions and directed to implement significantly different teaching me- 
thodology between the control and experimental conditions.

In contrast to the findings for the pre/post tests, the results from the student feedback were encouraging. On most of the items from the feedback form, the students rated the experimental (confluent education) condition as superior to the control (treatment as usual) condition. Students in the experimental condition seemed to feel that the confluence style of teaching increased their general learning and critical thinking skills more than the students in the control condition, although this difference was not present in regard to generalizing their learning to their potential abilities as a counselor.

\section{General Summary and Conclusions}

Confluent education refers to a humanistically oriented pedagogy. Using a humanistic foundation for the provision of education has a long history and has been revisited from time to time in different guises. In regard to graduate education in psychology, a prominent and successful school in Southern California, the Pacifica Graduate Institute was designed and operated incorporating a confluent education model. The current study sought to examine the academic effectiveness of this model, as well as its popularity with students. The results regarding academic effectiveness were inconclusive. The small sample sizes involved made the overall effect size statistically insignificant, although there was some evidence that the confluent education group improved more in rote memorization of academic material, a surprising result, given that one would expect that students taught in a "traditional" manner would do at least as well in this area, while confluent education students may do better in critical thinking. The most robust finding was that the students in the confluent education model liked the course more than the students in the control groups. This is not surprising. Confluent education, based on a humanistic model, focuses on an inclusive, holistic, fully engaged classroom. Learners at all levels, and particularly adult learners in the social sciences, can be expected to enjoy this experience more than the traditional, "sit and be lectured to" style of education.

The overall finding that the students enjoyed the confluent education more, and learned as least as much as the other students, is a positive initial finding for this model. Future studies should be done in order to overcome the statistical limitations of the small sample sizes in this initial study. This model of education, which has been well received and led to excellent results in schools such as the Pacifica Graduate Institute, could easily become a "calling card" for programs such as the MA in Counseling at National University. It would be particularly well-suited to courses and programs that utilize a "flipped classroom" where students are expected to study the academic material on their own and classroom time is spent engaging in more experiential learning to deepen and reinforce the learning, as well as integrate it with other areas of the students' knowledge and experience. This is particularly relevant in psychology, where everyone has "lived experience" in the subject area. In the confluent education model, instructors can spend more time leading students through experiences to 
practice skills, integrate knowledge, and particularly in the field of psychology, both integrate new information with and differentiate from previous beliefs and experience. Overall, the findings in this research reinforce the beliefs of humanistically oriented educators who support a more interactive, experiential, personalized, and personally relevant model of graduate education. The practical significance of this research is that program managers and developers can be confident that $\mathrm{CE}$ oriented programs can be academically successful and very popular with the students they serve.

\section{Acknowledgements}

The authors would like to thank Dr. Carol Richardson, Dean, College of Letters and Science, National University for her support of this project.

\section{Conflicts of Interest}

The authors declare no conflicts of interest regarding the publication of this paper.

\section{References}

Brown, G. (1971). Human Teaching for Human Learning: An Introduction to Confluent Education. New York, NY: Viking Press.

Brown, G. (Ed.) (1975). The Live Classroom: Innovation through Confluent Education and Gestalt. New York, NY: Penguin.

Chyung, S. Y. (2008). Foundations of Instructional and Performance Technology. Amherst, MA: HRD.

Doyle, T. (2011). Learner-Centered Teaching: Putting the Research on Learning into Practice. Sterling, VA: Stylus.

Kirkpatrick, D. L. (1996). Evaluating Training Programs: The Four Levels (3rd Ed.). San Francisco, CA: Berrett-Koehler.

Moore, K. (2005). Effective Instructional Practices: From Theory to Practice. New York, NY: McGraw-Hill.

Rogers, C. (1969). Freedom to Learn. Columbus, OH: Charles E. Merrill.

Rogers, C. (1983). Freedom to Learn for the 80's. New York, NY: Macmillan.

Shapiro, S. (1995). Training Effects of One Academic Year on Instructional Values of MA Students in Confluent Education and Counseling Psychology. Psychological Reports, 75, 225-226. https://doi.org/10.2466/pr0.1995.76.1.225

Shapiro, S. (1997). The UCSB Confluent Education Program: Its Essence and Demise. The Journal of Humanistic Psychology, 37, 80. https://doi.org/10.1177/00221678970373006

Urban, W. (2014). American Education: A History(5th Ed.). New York, NY: Routledge.

Wright, G. (2011). Student-Centered Learning in Higher Education. International Journal of Teaching and Learning in Higher Education, 23, 92-97. 


\section{Appendix A}

Pre and Post Tests and Feedback Form

PSY612A PRE-TEST

Multiple Choice-four points each

1) List four symptoms of a Manic Episode (one point for each correct answer):

a)

b)

c)

d)

2) List four different types of personality disorders:

a)

b)

c)

d)

3) An adult male displays a pattern of unstable and intense interpersonal relationships characterized by alternating between extremes of idealizations and devaluations, markedly and persistently unstable self-image or sense of self, impulsivity in at least two areas that are potentially self-damaging, recurrent suicidal behavior or self-mutilating behavior, and affective instability due to a marked reactivity of mood. An appropriate diagnosis would be:

a) Mood disorder, NOS

b) Social anxiety disorder

c) Agoraphobia disorder

d) Borderline personality disorder

4) On the MMPI-2, Scale 7, Pt, Psychasthenia, assesses:

a) Symptoms associated with a wide range of strange beliefs

b) Symptoms associated with depression and anxiety

c) Symptoms associated with a pattern of suspiciousness and mistrust

d) Symptoms associated with anxiety and obsessive-compulsive disorders

5) Fixed beliefs that are not amenable to change in light of conflicting evidence, are called?

a) Hallucinations

b) Delusions

c) Catatonia

d) Schizotypal disorder

6) You are conducting the assessment of a 40 -year-old, female client. Her speech is disorganized and reports to you that she has been feeling sad, losing sleep, eating more, and thinking about death. In addition, she states that prior to these new issues, she was experiencing delusions, did participate in family activities, and has not been able to work for the past nine months. She denied taking over-the-counter medications, using illegal drugs, nor drinking alcoholic beverages. 
The most likely diagnose will be:
a) Schizophreniform disorder
b) Delusional disorder
c) Schizotypal disorder
d) Schizoaffective disorder
7) A genogram, usually contains:
a) The last three generations
b) The first three generations
c) At least five generations
d) Seven generations
8) List four symptoms of schizophrenia:
a)
b)
c)
d)

9) Roger, a 22-year-old male arrives to your office with his parents for his initial clinical interview. $\mathrm{He}$ is reserved and makes poor eye contact. $\mathrm{He}$ is frequently looking at the walls and whispers as he looks around. His parents report to you that for the last three months, Roger has been spending time alone in his room, does not go out with his friends, has been seen talking to the walls and the voices in his head. The most likely diagnose would be:

a) Schizophrenia

b) Schizoaffective Disorder

c) Schizotypal Personality Disorder

d) Schizophreniform Disorder

10) In order to be diagnosed with personality disorder, an individual must be:
a) 12 years old
b) 16 years old
c) 18 years old
d) 21 years old
11) List four types of sexual dysfunctions:

a)

b)

c)

d)

12) Circle true or false (two points for each correct answer):

The older an individual is (60 years or older) the less the likelihood to be diagnosed with major depressive disorder:
a) True
b) False

The identified client is the family member that is causing the problem in the family:
a) True
b) False 
13) A dysphoric mood is described as:

a) Intense feelings of well-being and happiness

b) Intense feelings of elation and joy

c) Intense feelings of depression and discontent

d) Intense feelings including anger and anxiousness

14) On the MMPI-2, an elevated score on Scale 9 (Ma, Hypomania) indicates:

a) Manic symptoms

b) Psychotic symptoms

c) Symptoms associated with a pattern of suspiciousness and mistrust

d) Symptoms associated with anxiety and obsessive-compulsive disorders

15) In regard to psychotic features, negative symptoms include:

a) Poor behavior, negativistic attitude, and disobedience

b) Lack of movement, negativistic attitude, and poor adjustment

c) Affect flattening, poor eye contact, poverty of speech, and inability to initiate and persist in goal-directed activities

d) Affect flattening, poor eye contact, hyperactivity, and inability to initiate and persist in goal-directed activities

16) In assessing Schizophrenia, what are the some of the diagnostic criteria and duration of symptoms?

a) Delusions, hallucinations, disorganized thought, and the disturbance persists for at least 6 months. This six-month must include at least one month of symptoms

b) Delusions, hallucinations, disorganized thought, and the disturbance persists for at least one month

c) Delusions, hallucinations, disorganized thought, and the disturbance persists for at least 6 months. This six-month must include at least a week of symptoms

d) Delusions, mania, loss of appetite and weight, disturbance persist for at least 6 months. This six-month must include at least one month of symptoms

17) An adult that displays the following behaviors: Reckless disregard for safety of self or others; consistent irresponsibility, as indicated by repeated failure to sustain consistent work behavior or honor financial obligations; lack of remorse, as indicated by being indifferent to or rationalizing having hurt mistreated, or stolen from another; could be diagnosed with:

a) Conduct disorder

b) Antisocial personality disorder

c) Borderline personality disorder

d) Narcissistic personality disorder

18) These two symptoms must be in the diagnosis of major depressive disorder (circle both symptoms):
a) Depressed mood
b) Loss of interest or pleasure (anhedonia)
c) Significant weight loss or gain
d) Recurrent thoughts of death 
19) In regard to the prevalence for erectile disorder (circle all that apply):

a) Approximately $80 \%-90 \%$ of men ages $40-80$ years complain of occasional problems with erections

b) Approximately $2 \%$ of men younger than age ages 40 - 50 years complain of frequent problems with erections

c) Approximately $40 \%-50 \%$ of men older than 60 - 70 years may have significant problems with erections.

d) Approximately $95 \%$ of men 20 and younger do not complain about problems with erections

20) During the second session, your client shares with you that for the last six months, she has reduced genital sensations during sexual activity in all sexual encounters. She indicated feeling distress about this issue and how it is affecting her relationship with her partner. In addition, she reported a reduced interest in sexual activity, lack of erotic thoughts, and has not initiated sexual activity. The most likely diagnosis would be:

a) Female sexual interest/arousal disorder

b) Female sexual dysfunction

c) Female hypoactive sexual desire disorder

d) Female orgasmic disorder

21) In regard to premature ejaculation, approximately in how many minutes ejaculation occurs after vaginal penetration and before the individual wishes it?
a) One minute
b) Two minutes
c) Three minutes
d) Four minutes
a) Gender
b) Gender assignment
c) Gender experience
d) Gender dysphoria

22) The public lived role as a boy or a girl, man or woman is called?

23) The unique and personal ways in which individuals experience their gender in the context of the gender roles provided by their societies is called?
a) Gender dysphoria
b) Gender experience
c) Gender euphoria
d) Socio-cultural gender roles

24) The belief that certain gestures, comments, environmental cues, and so forth are directed at oneself is referred as:
a) Referential delusions
b) Persecutory delusions
c) Grandiose delusions
d) Erotomanic delusions

25) A disorder that results from damage to the parts of the brain that contain language, causes problems with any or all of the following: speaking, listening, 
reading, and writing. In addition, damage to the left side of the brain causes this disorder for most right-handers and about half of left-handers, is called:
a) Aphasia
b) Amnesia
c) Agnosia
d) Dystonia

PSY612A POST-TEST

Multiple Choice-four points each

1) A disorder that results from damage to the parts of the brain that contain language, causes problems with any or all of the following: speaking, listening, reading, and writing. In addition, damage to the left side of the brain causes this disorder for most right-handers and about half of left-handers, is called:
a) Amnesia
b) Agnosia
c) Dystonia
d) Aphasia
2) List four symptoms of a Manic Episode:
a)
b)
c)
d)

3) On the MMPI-2, Scale 7, Pt, Psychasthenia, assesses:

a) Symptoms associated with depression and anxiety

b) Symptoms associated with a pattern of suspiciousness and mistrust

c) Symptoms associated with anxiety and obsessive-compulsive disorders

d) Symptoms associated with a wide range of strange beliefs

4) A genogram, usually contains:

a) The last three generations

b) The first three generations

c) At least five generations

d) Seven generations

5) List four symptoms of schizophrenia:

a)

b)

c)

d)

6) David, a 22-year-old male arrives to your office with his girlfriend for his initial clinical interview. He is reserved and makes poor eye contact. He is frequently looking at the walls and whispers as he looks around. His girlfriend reports to you that for the last three months, David has been spending time alone in his room, does not go out with his friends, has been seen talking to the walls and the voices in his head. The most likely diagnose would be:

a) Schizophrenia

b) Schizoaffective Disorder 
c) Schizotypal Personality Disorder

d) Schizophreniform Disorder

7) In order to be diagnosed with personality disorder, an individual must be:
a) 12 years old
b) 16 years old
c) 18 years old
d) 21 years old
8) List four different types of personality disorders:
a)
b)
c)
d)

9) List four types of sexual dysfunctions:

a)

b)

c)

d)

10) Circle true or false (two points for each correct answer):

The older an individual is (60 years or older) the less the likelihood to be diagnosed with major depressive disorder:

a) True

b) False

The identified client is the family member that is causing the problem in the family:
a) True
b) False

11) A dysphoric mood is described as:

a) Intense feelings of well-being and happiness

b) Intense feelings of elation and joy

c) Intense feelings of depression and discontent

d) Intense feelings including anger and anxiousness

12) On the MMPI-2, an elevated score on Scale 9 (Ma, Hypomania) indicates:

a) Manic symptoms

b) Psychotic symptoms

c) Symptoms associated with a pattern of suspiciousness and mistrust

d) Symptoms associated with anxiety and obsessive-compulsive disorders

13) You are conducting the assessment of a 30-year-old, male client. His speech is disorganized and reports to you that he has been feeling sad, losing sleep, eating more, and thinking about death. In addition, he states that prior to these new issues, he was experiencing delusions, did participate in family activities, and has not been able to work for the past nine months. He denied taking over-the-counter medications, using illegal drugs, nor drinking alcoholic beverages. The most likely diagnose will be: 
a) Delusional disorder

b) Schizotypal disorder

c) Schizoaffective disorder

d) Schizophreniform disorder

14) An adult female displays a pattern of unstable and intense interpersonal relationships characterized by alternating between extremes of idealizations and devaluations, markedly and persistently unstable self-image or sense of self, impulsivity in at least two areas that are potentially self-damaging, recurrent suicidal behavior or self-mutilating behavior, and affective instability due to a marked reactivity of mood. An appropriate diagnosis would be:

a) Borderline personality disorder

b) Schizoaffective disorder

c) Social anxiety disorder

d) Agoraphobia disorder

15) In regard to psychotic features, negative symptoms include:

a) Poor behavior, negativistic attitude, and disobedience

b) Lack of movement, negativistic attitude, and poor adjustment

c) Affect flattening, poor eye contact, poverty of speech, and inability to initiate and persist in goal-directed activities

d) Affect flattening, poor eye contact, hyperactivity, and inability to initiate and persist in goal-directed activities

16) In assessing Schizophrenia, what are the some of the diagnostic criteria and duration of symptoms?

a) Delusions, hallucinations, disorganized thought, and the disturbance persists for at least 6 months. This six-month must include at least one month of symptoms

b) Delusions, hallucinations, disorganized thought, and the disturbance persists for at least one month

c) Delusions, hallucinations, disorganized thought, and the disturbance persists for at least 6 months. This six-month must include at least a week of symptoms

d) Delusions, mania, loss of appetite and weight, disturbance persist for at least 6 months. This six-month must include at least one month of symptoms

17) An adult that displays the following behaviors: Reckless disregard for safety of self or others; consistent irresponsibility, as indicated by repeated failure to sustain consistent work behavior or honor financial obligations; lack of remorse, as indicated by being indifferent to or rationalizing having hurt mistreated, or stolen from another; could be diagnosed with:

a) Conduct disorder

b) Antisocial personality disorder

c) Borderline personality disorder

d) Narcissistic personality disorder

18) Fixed beliefs that are not amenable to change in light of conflicting evidence, are called? 

a) Hallucinations
b) Delusions
c) Catatonia
d) Delusional disorder
19) These two symptoms must be in the diagnosis of major depressive disord- er (circle both symptoms):
a) Significant weight loss or gain
d) Recurrent thoughts of death
c) Depressed mood
d) Loss of interest or pleasure (anhedonia)

20) In regard to the prevalence for erectile disorder:

a) Approximately $10 \%$ - $12 \%$ of men ages 40 - 80 years complain of occasional problems with erections

b) Approximately $2 \%$ of men younger than age ages 40 - 50 years complain of frequent problems with erections

c) Approximately $10 \%-15 \%$ of men older than $60-70$ years may have significant problems with erections.

d) Approximately $90 \%$ of men 20 and younger complain about problems with erections

21) During the second session, your client shares with you that for the last six months, she has reduced genital sensations during sexual activity in all sexual encounters. She indicated feeling distress about this issue and how it is affecting her relationship with her partner. In addition, she reported a reduced interest in sexual activity, lack of erotic thoughts, and has not initiated sexual activity. The most likely diagnosis would be:

a) Female sexual interest/arousal disorder

b) Female sexual dysfunction

c) Female hypoactive sexual desire disorder

d) Female orgasmic disorder

22) In regard to premature ejaculation, approximately in how many minutes ejaculation occurs after vaginal penetration and before the individual wishes it?
a) One minute
b) Two minutes
c) Three minutes
d) Four minutes

23) The public lived role as a boy or a girl, man or woman is called?

a) Gender

b) Gender assignment

c) Gender experience

d) Gender dysphoria

24) The unique and personal ways in which individuals experience their gender in the context of the gender roles provided by their societies is called?

a) Gender dysphoria

b) Gender experience 
c) Gender euphoria

d) Socio-cultural gender roles

25) The belief that certain gestures, comments, environmental cues, and so forth are directed at oneself is referred as:
a) Referential delusions
b) Persecutory delusions
c) Grandiose delusions
d) Erotomanic delusions

\section{Appendix B}

Student Feedback Form-PSY612A

Please checkmark the answer that is most true for you

1) My writing skills have improved

a) Disagree

b) Agree a little

c) Agree somewhat

d) Agree moderately

e) Agree a lot

2) My oral communication skills have improved

a) Disagree

b) Agree a little

c) Agree somewhat

d) Agree moderately

e) Agree a lot

3) I gained significant knowledge about this subject

a) Disagree

b) Agree a little

c) Agree somewhat

d) Agree moderately

e) Agree a lot

4) My ability to think critically about the topics in this class has improved

a) Disagree

b) Agree a little

c) Agree somewhat

d) Agree moderately

e) Agree a lot

5) I feel I can apply what I learned in this course beyond the classroom

a) Disagree

b) Agree a little

c) Agree somewhat

d) Agree moderately

e) Agree a lot

6) The teaching techniques used in the classroom helped me learn the subject 

a) Disagree
b) Agree a little
c) Agree somewhat
d) Agree moderately
e) Agree a lot
7) Methods used to assess learning (tests, papers, presentation, etc.) were valid measures of how much I learned
a) Disagree
b) Agree a little
c) Agree somewhat
d) Agree moderately
e) Agree a lot
8) The Instruction methods stimulated critical and independent thinking
a) Disagree
b) Agree a little
c) Agree somewhat
d) Agree moderately
e) Agree a lot
9) The Classroom activities helped me achieve the course learning outcomes
a) Disagree
b) Agree a little
c) Agree somewhat
d) Agree moderately
e) Agree a lot
10) Overall, the way the course was taught was effective and helped me in the development of knowledge and skills related to the topic
a) Disagree
b) Agree a little
c) Agree somewhat
d) Agree moderately
e) Agree a lot

11) This course has helped me identify my strengths and weaknesses as a student.
a) Disagree
b) Agree a little
c) Agree somewhat
d) Agree moderately
e) Agree a lot
a) Disagree
b) Agree a little
c) Agree somewhat
d) Agree moderately
e) Agree a lot

12) I feel that this course has helped prepare me to be a better counselor 


\section{Appendix C}

\begin{tabular}{|c|c|c|}
\hline \multicolumn{3}{|c|}{ Confluent Educatio } \\
\hline \multicolumn{3}{|c|}{ Measure Scoring Guide } \\
\hline Pre answ area & Post answ area & Feedback area \\
\hline 1) $4 \mathrm{sx} \mathrm{Dx}$ & 1) $\mathrm{B} \mathrm{Dx}$ & 1) Gen Learn \\
\hline 2) $4 \mathrm{pd} \mathrm{Dx}$ & 2) $4 \mathrm{sx} \mathrm{Dx}$ & 2) Gen Learn \\
\hline 3) D Crit & 3) C Rote & 3) Gen Learn \\
\hline 4) D Rote & 4) A Rote & 4) Crit think \\
\hline 5) B Dx & 5) $4 \mathrm{sx} \mathrm{Dx}$ & 5) Generalize \\
\hline 6) D Crit & 6) D Crit & 6) Confluent \\
\hline 7) A Rote & 7) C Dx & 7) Confluent \\
\hline 8) $4 \mathrm{sx} \mathrm{Dx}$ & 8) $4 \mathrm{pd} \mathrm{Dx}$ & 8) Crit think \\
\hline 9) D Crit & 9) $4 \mathrm{pd} \mathrm{Dx}$ & 9) Confluent \\
\hline 10) C Dx & 10) $t / f$ Rote & 10) Confluent \\
\hline 11) $4 \mathrm{Dx} \mathrm{Dx}$ & 11) C Dx & 11) Gen Learn \\
\hline 12) f/f Rote & 12) A Rote & 12) Generalize \\
\hline 13) C Dx & 13) C Crit & \\
\hline 14) A Rote & 14) A Crit & \\
\hline 15) C Dx & 15) C Dx & \\
\hline 16) A Dx & 16) A Dx & \\
\hline 17) B Crit & 17) B Crit & \\
\hline 18) $\mathrm{A} / \mathrm{B} \mathrm{Dx}$ & 18) B Dx & \\
\hline 19) C Rote & 19) C \& D Dx & \\
\hline 20) A Crit & 20) B Rote & \\
\hline 21) A Dx & 21) A Crit & \\
\hline 22) A Rote & 22) A Dx & \\
\hline 23) B Rote & 23) B Rote & \\
\hline 24) A Rote & 24) B Rote & \\
\hline 25) A Dx & 25) A Rote & \\
\hline
\end{tabular}

